\title{
Đa dạng hệ thực vật ở thị xã Duyên Hải tỉnh Trà Vinh
} Flora diversity in Duyen Hai town of Tra Vinh province

\author{
Đặng Văn Sơn ${ }^{1 *}$, Hoàng Nghĩa Sơn ${ }^{1}$, Trần Văn Tiến ${ }^{1}$, Nguyễn Văn Tú1 \\ ${ }^{1}$ Viện Sinh học Nhiệt đới, Viện Hàn lâm Khoa học và Công nghệ, Việt Nam \\ *Tác giả liên hệ, Email: dvsonitb@gmail.com
}

THÔNG TIN

DOI:10.46223/HCMCOUJS. tech.vi.13.1.453.2018

Ngày nhận: 17/07/2018

Ngày nhận lại: 06/08/2018

Duyệt đăng: 15/10/2018

Tù khóa:

đa dạng thực vật, Duyên Hải, sinh cảnh thực vật, Trà Vinh

Keywords:

Duyen Hai, floral diversity, floral habitat, Tra Vinh

\section{TÓM TÁT}

Từ kết quả nghiên cứu đã xác định được ở thị xã Duyên Hải tỉnh Trà Vinh có 273 loài, 209 chi, 78 họ của 2 ngành thực vật bậc cao có mạch là ngành Dương xỉ (Polypodiophyta) và ngành Ngọc lan (Magnoliophyta). Giá trị sử dụng của thực vật cũng được thống kê và chia làm 5 nhóm gồm: làm thuốc có 186 loài, làm cảnh có 26 loài, cho gỗ có 15 loài, thực phẩm có 15 loài, và gia dụng có 6 loài. Dạng thân của thực vật được chia làm 6 nhóm chính là cây thân thảo có 141 loài, cây bụi có 46 loài, dây leo có 36 loài, gỗ nhỏ có 25 loài, gỗ lớn có 22 loài và bán ký sinh có 3 loài. Đồng thời, ghi nhận được 3 kiểu sinh cảnh thực vật hiện diện ở khu vực nghiên cứu là Sinh cảnh thực vật tự nhiên (với 7 kiểu quần hợp), Sinh cảnh thực vật trên đất canh tác và Sinh cảnh thực vật trên đất thổ cư.

\begin{abstract}
The study investigated the floral diversity in Duyen Hai town of Tra Vinh province and recorded 273 species, 209 genera and 78 families belonging to the two high-rank phyla of vascular plants including Lycopodiophyta and Magnoliophyta. The plant resources were also divided into five groups as follows: (1) medicinal plants with 186 species, (2) ornamental plants with 26 species, (3) wood plants with 15 species, (4) foodstuff with 15 species and (5) household plants with 6 species. Life forms of plants were divided into six groups including herbs with 141 species, shrubs with 46 species, lianas with 36 species, small trees with 25 species, big trees with 22 species and hemiparasites with 3 species. Moreover, 3 habitats including habitat with natural flora (with 7 plant communities), habitat with the flora of farming land and habitat with the flora of land tenure were identified.
\end{abstract}

\section{Mở đầu}

Thị xã Duyên Hải được thành lập ngày 15/5/2015 theo Nghị quyết số 934/NQUBTVQH13 của Ủy ban Thường vụ Quốc hội trên cơ sở điều chỉnh địa giới hành chính huyện 
Trà Cú và Duyên Hải của tỉnh Trà Vinh. Thị xã Duyên Hải nằm ở phía Nam của tỉnh, có 7 đơn vị hành chính gồm: 2 phường là Phường 1,2 và 5 xã là Long Toàn, Long Hữu, Hiệp Thạnh, Trường Long Hòa và Dân Thành; có tọa độ địa lý từ $9^{0} 34^{\prime} 27^{\prime \prime}$ đến $9^{0} 47^{\prime} 17^{\prime \prime}$ vĩ độ Bắc và từ $106^{0} 30^{\prime} 45^{\prime}$ " đến $106^{0} 33$ '21" kinh độ Đông; phía đông giáp với Biển Đông, phía tây và nam giáp với huyện Duyên Hải, phía Bắc giáp huyện Cầu Ngang, với tổng diện tích tự nhiên 17.709,64 ha. Đây là thị xã mới thành lập nên chưa có một nghiên cứu nào đề cập đến tính đa dạng của nguồn tài nguyên thực vật, do đó việc điều tra xác định tính đa dạng của loài cũng như các sinh cảnh thực vật cho thị xã Duyên Hải nhằm phục vụ công tác quy hoạch, bảo tồn và phát triển bền vững nguồn tài nguyên đa dạng thực vật là điều rất cần thiết ở hiện tại và trong tương lai.

\section{Vật liệu và phương pháp nghiên cứu}

\subsection{Vật liệu}

Toàn bộ thành phần loài và sinh cảnh thực vật ở thị xã Duyên Hải tỉnh Trà Vinh.

\subsection{Phương pháp nghiên cúu}

Tiến hành điều tra theo tuyến thông qua các sinh cảnh đại diện để thu mẫu thực vật phục vụ nghiên cứu, thời gian điều tra được thực hiện trong 3 đợt, mỗi đợt từ 5-7 ngày (tháng $12 / 2016$, tháng 3 và $8 / 2017$ ); mẫu vật sau khi thu ngoài thực địa được xử lý sơ bộ, chụp ảnh và ghi chép lý lịch mẫu.

Sử dụng phương pháp Braun-Blanquet (1964) để xác định các quần hợp thực vật ở khu vực nghiên cứu. Để đơn giản trong việc thực hiện ngoài thực địa chúng tôi chọn ô mẫu với kích thước tương đối cho các kiểu sinh cảnh khác nhau: ô mẫu có kích thước $20 \mathrm{~m} \times 20 \mathrm{~m}$ đối với quần hợp cây gỗ và cây bụi; $1 \mathrm{~m} x 1 \mathrm{~m}$ đối với quần hợp đồng cỏ. Tiến hành thu mẫu vật trong mỗi ô để xác định thành phần loài, mô tả đặc điểm sinh cảnh và ước lượng loài ưu thế.

Giám định tên khoa học của thực vật theo phương pháp hình thái so sánh dựa theo các tài liệu chuyên ngành như: Cây cỏ Việt Nam (Pham, 1999), Cẩm nang tra cứu và nhận biết các họ thực vật hạt kín ở Việt Nam (T. B. Nguyen, 1997), Thực vật chí Việt Nam (tập 1-11) (Bộ Khoa học và Công nghệ \& Viện Khoa học và Công nghệ Việt Nam, 2007), ... đồng thời so mẫu với bộ mẫu chuẩn được lưu giữ ở Bảo tàng thực vật thuộc Viện Sinh học nhiệt đới, Viện Hàn lâm Khoa học và Công nghệ Việt Nam. Xác định dạng thân của thực vật theo tài liệu của Pham (1999) và T. N. Nguyen $(1997,2007)$. Xác định giá trị sử dụng và giá trị bảo tồn theo tài liệu của Vo (2012), L. T. Do (2009), B. H. Do (2006) và Bộ Khoa học và Công nghệ (2007).

\section{Kết quả và thảo luận}

\subsection{Thành phần loài}

Từ kết quả phân tích ngoài thực địa và trong phòng thí nghiệm đã xác định được thành phần loài thực vật ở thị xã Duyên Hải tỉnh Trà Vinh có 273 loài, 209 chi, 78 họ của 2 ngành thực vật có mạch là Dương xỉ (Polypodiophyta) và Ngọc lan (Magnoliophyta). Trong đó, ngành Dương xỉ có 7 loài (chiếm 2,6\% tổng số loài), 5 chi (chiếm 2,4\% tổng số chi), 4 họ (chiếm $5,1 \%$ tổng số họ); ngành Ngọc lan có 266 loài (chiếm 97,4\%), 204 chi (chiếm 97,6\%), 74 họ (chiếm $94,9 \%$ ). Như vậy, từ số liệu cho thấy ngành Ngọc lan chiếm ưu thế trong hệ thực vật ở khu vực nghiên cứu (Bảng 1). 


\section{Bảng 1}

Danh mục thành phần loài thực vật ở thị xã Duyên Hải, tỉnh Trà Vinh

\begin{tabular}{|c|c|c|c|c|}
\hline STT & Tên khoa học & Tên việt nam & Dạng thân & $\begin{array}{l}\text { Công } \\
\text { dung }\end{array}$ \\
\hline & I. POLYPODIOPHYTA & $\underset{\text { Xİ }}{\text { NGÀNH DƯONG }}$ & & \\
\hline & 1. Blechnaceae & Họ Dây choại & & \\
\hline \multirow[t]{2}{*}{1} & $\begin{array}{l}\text { Stenochlaena palustris (Burm. f.) } \\
\text { Bedd. }\end{array}$ & Dây choại & DL & $\mathrm{T}$ \\
\hline & 2. Pteridaceae & Họ Ráng chân xỉ & & \\
\hline 2 & Acrostichum aureum L. & Ráng đại & $\mathrm{C}$ & $\mathrm{T}$ \\
\hline \multirow[t]{2}{*}{3} & $\begin{array}{l}\text { Ceratopteris thalictroides (L.) } \\
\text { Brongn. }\end{array}$ & Ráng gạt nai & $\mathrm{C}$ & $\mathrm{T}$ \\
\hline & 3. Salviniaceae & Họ Bèo tai chuột & & \\
\hline \multirow[t]{2}{*}{4} & Salvinia cucullata Roxb. & Bèo tai chuột & $\mathrm{C}$ & $\mathrm{LC}$ \\
\hline & 4. Schizeaceae & Họ Ráng a diệp & & \\
\hline 5 & Lygodium flexuosum (L.) Sw & Bòng bòng dẻo & DL & $\mathrm{T}$ \\
\hline 6 & $\begin{array}{l}\text { Lygodium japonicum (Thunb.) } \\
\text { Sw. }\end{array}$ & Bòng bòng & DL & $\mathrm{T}$ \\
\hline \multirow[t]{4}{*}{7} & Lygodium scandens (L.) Sw. & Bòng bòng leo & DL & $\mathrm{T}$ \\
\hline & II. MAGNOLIOPHYTA & $\begin{array}{c}\text { NGÀNH NGQ̣C } \\
\text { LAN } \\
\end{array}$ & & \\
\hline & MAGNOLIOPSIDA & LỚP NGỌC LAN & & \\
\hline & 5. Acanthaceae & Họ Ô rô & & \\
\hline 8 & Acanthus ebracteatus Vahl. & Ô rô trắng & $\mathrm{B}$ & $\mathrm{T}$ \\
\hline 9 & Acanthus ilicifolius L. & Ô rô & $\mathrm{B}$ & $\mathrm{T}$ \\
\hline 10 & $\begin{array}{l}\text { Asystasia gangetica (L.) T. } \\
\text { Anders. }\end{array}$ & $\begin{array}{l}\text { Biến hoa sông } \\
\text { hằng }\end{array}$ & $\mathrm{C}$ & $\mathrm{T}$ \\
\hline 11 & Barleria lupulina Lindl. & Gai kim vàng & $\mathrm{B}$ & $\mathrm{LC}$ \\
\hline 12 & $\begin{array}{l}\text { Hygrophila erecta (Burm.f.) } \\
\text { Hochr. }\end{array}$ & Đình lịch đứng & $\mathrm{C}$ & \\
\hline 13 & Ruellia tuberosa $\mathrm{L}$. & Trái nổ & $\mathrm{C}$ & $\mathrm{T}$ \\
\hline \multirow[t]{2}{*}{14} & $\begin{array}{l}\text { Thunbergia grandiflora (Rottl.) } \\
\text { Roxb. }\end{array}$ & Cát đằng hoa to & DL & $\mathrm{T}$ \\
\hline & 6. Aizoaceae & Họ Rau đắng đất & & \\
\hline 15 & $\begin{array}{l}\text { Glinus oppositifolius (L.) } \\
\text { Aug.DC. }\end{array}$ & Rau đắng đất & $\mathrm{C}$ & $\mathrm{T}$ \\
\hline 16 & Sesuvium portulacastrum (L.) L. & Hải châu & $\mathrm{C}$ & $\mathrm{T}$ \\
\hline \multirow[t]{2}{*}{17} & Trianthema portulacastrum L. & Cỏ tam khôi & $\mathrm{C}$ & $\mathrm{T}$ \\
\hline & 7. Amaranthaceae & Họ Rau dền & & \\
\hline 18 & Achyranthes aspera L. & Cỏ sướt & $\mathrm{C}$ & $\mathrm{T}$ \\
\hline
\end{tabular}




\begin{tabular}{|c|c|c|c|c|}
\hline STT & Tên khoa học & Tên việt nam & Dạng thân & $\begin{array}{l}\text { Công } \\
\text { dụng }\end{array}$ \\
\hline 19 & $\begin{array}{l}\text { Alternanthera ficoidea (L.) P. } \\
\text { Beauv. }\end{array}$ & Diếc & $\mathrm{C}$ & $\mathrm{T}$ \\
\hline 20 & $\begin{array}{l}\text { Alternanthera sessilis (L.) R.Br. } \\
\text { ex DC. }\end{array}$ & Diếc bờ & $\mathrm{C}$ & $\mathrm{T}$ \\
\hline 21 & Amaranthus lividus L. & Dền tái & $\mathrm{C}$ & $\mathrm{TP}$ \\
\hline 22 & Amaranthus spinosus $\mathrm{L}$. & Dền gai & $\mathrm{C}$ & $\mathrm{TP}$ \\
\hline \multirow[t]{2}{*}{23} & Celosia argentea $\mathrm{L}$. & Mào gà & $\mathrm{C}$ & LC \\
\hline & 8. Annonaceae & Họ Na & & \\
\hline \multirow[t]{2}{*}{24} & Annona glabra L. & Bình bát & B & $\mathrm{TP}$ \\
\hline & 9. Apiaceae & Họ Ngò & & \\
\hline \multirow[t]{2}{*}{25} & Centella asiatica (L.) Urb. & Rau má & $\mathrm{C}$ & $\mathrm{TP}$ \\
\hline & 10. Apocynaceae & Họ Trúc đào & & \\
\hline 26 & Allamanda schottii Pohl & Huỳnh anh lá hẹp & $\mathrm{DL}$ & $\mathrm{T}$ \\
\hline 27 & Cascabela thevetia (L.) Lippold & Thông thiên & $\mathrm{B}$ & $\mathrm{T}$ \\
\hline 28 & Catharanthus roseus (L.) G. Don & Dừa cạn & $\mathrm{C}$ & $\mathrm{LC}$ \\
\hline 29 & Cerbera odollam Gaertn. & Mướp xác & GN & $\mathrm{T}$ \\
\hline 30 & $\begin{array}{l}\text { Gymnanthera oblonga (Burm.f.) } \\
\text { P.S.Green }\end{array}$ & Lõa hùng & DL & \\
\hline 31 & Strophanthus caudatus (L.) Kurz & Sừng trâu & $\mathrm{B}$ & $\mathrm{T}$ \\
\hline 32 & Tylophora flexuosa $\mathrm{R}$. Br. & Đầu đài mảnh & $\mathrm{DL}$ & \\
\hline \multirow[t]{2}{*}{33} & $\begin{array}{l}\text { Wrightia pubescens subsp. lanati } \\
\text { (BL.) Ngan. }\end{array}$ & Lòng mức lông & GN & G \\
\hline & 11. Araliaceae & Họ Đinh lăng & & \\
\hline 34 & Polyscias fruticosa (L.) Harms & Đinh lăng & $\mathrm{B}$ & $\mathrm{T}$ \\
\hline \multirow[t]{2}{*}{35} & $\begin{array}{l}\text { Schefflera elliptica (Blume) } \\
\text { Harms }\end{array}$ & Chân chim bầu dục & B & $\mathrm{LC}$ \\
\hline & 12. Asclepiadaceae & Họ Thiên lý & & \\
\hline 36 & Calotropis gigantea $(\mathrm{L}$.$) Dryand.$ & Bòng bòng & $\mathrm{B}$ & $\mathrm{T}$ \\
\hline 37 & Finlayasonia obovata Wall. & Dây mủ & DL & TP \\
\hline 38 & $\begin{array}{l}\text { Gymnanthera oblonga (Burm.f.) } \\
\text { P.S.Green }\end{array}$ & Lõa hùng & DL & \\
\hline 39 & Oxystelma esculentum (L. f.) Sm. & Cù mai & DL & \\
\hline 40 & Sarcolobus globosus Wall. & Dây cám & $\mathrm{DL}$ & $\mathrm{T}$ \\
\hline 41 & Toxucarpus villosus (B1.) Decne & Tiễn quả & $\mathrm{DL}$ & $\mathrm{T}$ \\
\hline 42 & Tylophora flexuosa R. Br. & Đầu đài mảnh & DL & \\
\hline 43 & Tylophora indica (Burm. f.) Merr. & Đầu đài ấn & $\mathrm{DL}$ & $\mathrm{T}$ \\
\hline 44 & $\begin{array}{l}\text { Tylophora ovata (Lindl.) Hook. ex } \\
\text { Steud. }\end{array}$ & Đầu đài & DL & \\
\hline
\end{tabular}




\begin{tabular}{|c|c|c|c|c|}
\hline STT & Tên khoa học & Tên việt nam & Dạng thân & $\begin{array}{l}\text { Công } \\
\text { dụng }\end{array}$ \\
\hline & 13. Asteraceae & Họ Cúc & & \\
\hline 45 & Ageratum conyzoides $(\mathrm{L}.) \mathrm{L}$. & Cỏ cứt lợn & $\mathrm{C}$ & $\mathrm{T}$ \\
\hline 46 & Bidens pilosa $\mathrm{L}$. & Song nha lông & $\mathrm{C}$ & $\mathrm{T}$ \\
\hline 47 & Blainvillea acmella (L.) Philipson & Núc vàng & $\mathrm{C}$ & \\
\hline 48 & Blumea lacera (Burm.f.) DC. & Kim đầu & $\mathrm{C}$ & $\mathrm{T}$ \\
\hline 49 & Eclipta prostrata $(\mathrm{L}.) \mathrm{L}$. & Cỏ nhọ nồi & $\mathrm{C}$ & $\mathrm{T}$ \\
\hline 50 & Enydra fluctuans DC. & Rau ngổ & $\mathrm{C}$ & $\mathrm{T}$ \\
\hline 51 & Eupatorium odoratum L. & Cộng sản & $\mathrm{C}$ & $\mathrm{T}$ \\
\hline 52 & Galinsoga parviflora Cav. & Vi cúc & $\mathrm{C}$ & \\
\hline 53 & $\begin{array}{l}\text { Grangea maderaspatana (L.) } \\
\text { Poir. }\end{array}$ & Cải đồng & $\mathrm{C}$ & \\
\hline 54 & Lactuca indica $\mathrm{L}$. & Bồ công anh & $\mathrm{C}$ & $\mathrm{T}$ \\
\hline 55 & Pluchea indica (L.) Less. & Lức & B & $\mathrm{T}$ \\
\hline 56 & $\begin{array}{l}\text { Pluchea pteropoda Hemsl. ex } \\
\text { Hemsl. }\end{array}$ & Sài hồ & $\mathrm{C}$ & $\mathrm{T}$ \\
\hline 57 & Sphaeranthus indicus L. & Chân vịt ấn & $\mathrm{C}$ & $\mathrm{T}$ \\
\hline 58 & Synedrella nodiflora (L.) Gaertn. & Bọ xít & $\mathrm{C}$ & \\
\hline 59 & Tridax procumbens $\mathrm{L}$. & Cúc mui & $\mathrm{C}$ & $\mathrm{T}$ \\
\hline 60 & Vernonia cinerea (L.) Less. & Bạch đầu ông & $\mathrm{C}$ & $\mathrm{T}$ \\
\hline 61 & Wollastonia biflora (L.) DC. & Hải cúc 2 hoa & $\mathrm{C}$ & $\mathrm{T}$ \\
\hline \multirow[t]{2}{*}{62} & Xanthium inaequilaterum DC. & Ké đầu ngựa & $\mathrm{C}$ & $\mathrm{T}$ \\
\hline & 14. Bignoniaceae & Họ Quao & & \\
\hline 63 & Crescentia cujete $\mathrm{L}$. & Đào tiên & GN & LC \\
\hline 64 & $\begin{array}{l}\text { Dolichandrone spathacea (L.f.) } \\
\text { Seem. }\end{array}$ & Quao nước & GN & G \\
\hline \multirow[t]{2}{*}{65} & Tecoma stans (L.)H.B.K. & Huỳnh liên & $\mathrm{B}$ & LC \\
\hline & 15. Boraginaceae & Họ Vòi voi & & \\
\hline 66 & $\begin{array}{l}\text { Carmone microphylla (Lam.) } \\
\text { Don. }\end{array}$ & Cụm rụm & B & \\
\hline \multirow[t]{2}{*}{67} & Heliotropium indicum $\mathrm{L}$. & Vòi voi & $\mathrm{C}$ & $\mathrm{T}$ \\
\hline & 16. Casuarinaceae & Họ Phi lao & & \\
\hline \multirow[t]{2}{*}{68} & $\begin{array}{l}\text { Casuarina equisetifolia J.R et G. } \\
\text { Forst }\end{array}$ & Phi lao & GN & $\mathrm{T}, \mathrm{LC}$ \\
\hline & 17. Chenopodiaceae & Họ Kinh giới & & \\
\hline \multirow[t]{2}{*}{69} & Suaeda maritima (L.) Dumort. & Muối biển & $\mathrm{C}$ & $\mathrm{TP}$ \\
\hline & 18. Cleomaceae & Họ Màn màn & & \\
\hline 70 & Cleome chelidonii L.f. & Màn màn tím & $\mathrm{C}$ & $\mathrm{T}$ \\
\hline 71 & Cleome viscosa $\mathrm{L}$. & Màn màn trĩn & $\mathrm{C}$ & $\mathrm{T}$ \\
\hline
\end{tabular}




\begin{tabular}{|c|c|c|c|c|}
\hline STT & Tên khoa học & Tên việt nam & Dạng thân & $\begin{array}{l}\text { Công } \\
\text { dụng }\end{array}$ \\
\hline & 19. Clusiaceae & Họ Bứa & & \\
\hline \multirow[t]{2}{*}{72} & Calophyllum inophyllum $\mathrm{L}$. & Mù u & GL & $\mathrm{G}$ \\
\hline & 20. Combretaceae & Họ Bàng & & \\
\hline 73 & Combretum quadrangulare Kurz. & Chưn bầu & GN & $\mathrm{G}$ \\
\hline \multirow[t]{2}{*}{74} & Terminalia catappa $\mathrm{L}$. & Bàng & GL & $\mathrm{LC}$ \\
\hline & 21. Convolvulaceae & Họ Bìm bìm & & \\
\hline 75 & $\begin{array}{l}\text { Aniseia martinicensis (Jacq.) } \\
\text { Choisy }\end{array}$ & Bìm nước & DL & $\mathrm{T}$ \\
\hline 76 & Ipomoea maxima Don ex Sweet & Bìm nhỏ & DL & \\
\hline 77 & Ipomoea pes-caprae (L.) R. Br. & Muống biển & $\mathrm{DL}$ & $\mathrm{T}$ \\
\hline 78 & Ipomoea pes-tigridis $\mathrm{L}$. & Bìm chân cọp & DL & $\mathrm{T}$ \\
\hline 79 & Ipomoea triloba $\mathrm{L}$ & Bìm ba răng & $\mathrm{DL}$ & \\
\hline \multirow[t]{2}{*}{80} & $\begin{array}{l}\text { Merremia hederacea (Burm. f.) } \\
\text { Hallier f. }\end{array}$ & Bìm vàng & DL & \\
\hline & 22. Cucurbitaceae & Họ Bầu bí & & \\
\hline 81 & Coccinia grandis (L.) Voigt & Bát & DL & $\mathrm{T}$ \\
\hline \multirow[t]{2}{*}{82} & $\begin{array}{l}\text { Gymnopetalum chinense (Lour.) } \\
\text { Merr. }\end{array}$ & Cứt quạ & DL & $\mathrm{T}$ \\
\hline & 23. Dipterocarpaceae & Họ Dầu & & \\
\hline 83 & Dipterocarpus alatus Roxb & Dầu rái & GL & $\mathrm{LC}$ \\
\hline \multirow[t]{2}{*}{84} & Hopea odorata $\mathrm{L}$. & Sao đen & GL & LC, G \\
\hline & 24. Elaeocarpaceae & Họ Côm & & \\
\hline \multirow[t]{2}{*}{85} & $\begin{array}{l}\text { Elaeocarpus griffithii (Wight) } \\
\text { A.Gray }\end{array}$ & Côm & GL & G \\
\hline & 25. Euphorbiaceae & Họ Thầu dầu & & \\
\hline 86 & Acalypha indica $\mathrm{L}$. & Tai tượng ấn & $\mathrm{C}$ & $\mathrm{T}$ \\
\hline 87 & Antidesma ghaesembilla Gaertn. & Chòi mòi & GN & \\
\hline 88 & $\begin{array}{l}\text { Breynia vitis-idaea (Burn.f) C.E.C } \\
\text { Fischer. }\end{array}$ & Cù đề & B & $\mathrm{T}$ \\
\hline 89 & Euphorbia heterophylla $\mathrm{L}$. & Cỏ mủ & $\mathrm{C}$ & \\
\hline 90 & Euphorbia hirta L. & Cỏ sữa lá lớn & $\mathrm{C}$ & $\mathrm{T}$ \\
\hline 91 & Excoecaria cochinchinensis Lour. & Đơn đỏ & $\mathrm{B}$ & $\mathrm{T}$ \\
\hline 92 & Excoecaria agallocha $\mathrm{L}$ & Giá & GN & $\mathrm{T}$ \\
\hline 93 & Glochidion littorale Bl. & Bọt ếch biển & B & $\mathrm{T}$ \\
\hline 94 & Hura crepitans $\mathrm{L}$. & Mã đậu & GL & \\
\hline 95 & Jatropha multifida L. & Dầu lai nhiều khía & $\mathrm{B}$ & $\mathrm{T}$ \\
\hline 96 & Ricinus communis L. & Thầu dầu & B & $\mathrm{T}$ \\
\hline & 26. Fabaceae & Họ Đậu & & \\
\hline
\end{tabular}




\begin{tabular}{|c|c|c|c|c|}
\hline STT & Tên khoa học & Tên việt nam & Dạng thân & $\begin{array}{l}\text { Công } \\
\text { dụng }\end{array}$ \\
\hline 97 & Abrus precatorius L. & Cam thảo dây & DL & $\mathrm{T}$ \\
\hline 98 & Aeschynomene americana $\mathrm{L}$. & Điền ma & $\mathrm{C}$ & \\
\hline 99 & Canavalia cathartica Thouars & Đậu cộ & $\mathrm{DL}$ & $\mathrm{T}$ \\
\hline 100 & Cassia occidentalis $\mathrm{L}$. & Muồng tây & $\mathrm{B}$ & $\mathrm{T}$ \\
\hline 101 & Cassia tora $\mathrm{L}$. & Thảo quyết minh & $\mathrm{C}$ & \\
\hline 102 & Crotalaria pallida Aiton & Lục lạc ba lá & $\mathrm{C}$ & $\mathrm{T}$ \\
\hline 103 & Derris trifolia Lour. & Cóc kèn & DL & $\mathrm{T}$ \\
\hline 104 & $\begin{array}{l}\text { Desmodium heterophyllum } \\
\text { (Willd.) DC. }\end{array}$ & Hàn the & $\mathrm{C}$ & $\mathrm{T}$ \\
\hline 105 & $\begin{array}{l}\text { Desmodium oblatum Bak. ex } \\
\text { Kurz. }\end{array}$ & Tràng quả & $\mathrm{C}$ & \\
\hline 106 & $\begin{array}{l}\text { Leucaena leucocephala (Lam.) de } \\
\text { Wit }\end{array}$ & Bọ chét, keo & B & $\mathrm{T}$ \\
\hline 107 & Mecopus nidulans Benth. & Ố chim & $\mathrm{C}$ & $\mathrm{T}$ \\
\hline 108 & Mimosa pigra $\mathrm{L}$ & Mai dương & B & \\
\hline 109 & Mimosa pudica $\mathrm{L}$. & Mắc cở & $\mathrm{C}$ & $\mathrm{T}$ \\
\hline 110 & Neptunia oleracea Lour. & Rau nhút & $\mathrm{C}$ & $\mathrm{T}$ \\
\hline 111 & Pachyrrhizus erosus (L.) Urban. & Sắn dây & $\mathrm{DL}$ & $\mathrm{T}$ \\
\hline 112 & $\begin{array}{l}\text { Peltophorum pterocarpum (DC.) } \\
\text { K.Heyne }\end{array}$ & Lim xẹt & GL & LC \\
\hline 113 & Senna alata (L.) Roxb. & Muồng trâu & B & $\mathrm{T}$ \\
\hline 114 & Sesbania cannabina (Retz.) Pers. & Điên điển & $\mathrm{C}$ & $\mathrm{T}, \mathrm{TP}$ \\
\hline 115 & Sesbania grandiflora (L.) Pers. & So đũa & GN & $\mathrm{T}, \mathrm{TP}$ \\
\hline \multirow[t]{2}{*}{116} & $\begin{array}{l}\text { Vigna adenantha (G.F.Mey) Mar. } \\
\text { Masch. \& Stain. }\end{array}$ & Đậu hoa tuyến & DL & $\mathrm{T}$ \\
\hline & 27. Lamiaceae & Họ Hoa môi & & \\
\hline 117 & Hyptis capitata Jacq. & É lớn đầu & $\mathrm{C}$ & $\mathrm{T}$ \\
\hline 118 & Leonurus artemisia (Lour.) $\mathrm{Hu}$ & Ích mẫu & $\mathrm{C}$ & \\
\hline 119 & Leucas zeylanica (L.) R.Br. & Mè đất & $\mathrm{C}$ & $\mathrm{T}$ \\
\hline 120 & Ocimum gratissimum $\mathrm{L}$. & Hương nhu trắng & $\mathrm{C}$ & $\mathrm{T}$ \\
\hline \multirow[t]{2}{*}{121} & Prunella vulgaris L. & Hạ khô thảo & $\mathrm{C}$ & $\mathrm{T}$ \\
\hline & 28. Lauraceae & Họ Long não & & \\
\hline 122 & Cassytha filiformis $\mathrm{L}$. & Dây tơ xanh & $\mathrm{C}$ & $\mathrm{T}$ \\
\hline 123 & $\begin{array}{l}\text { Cinnamoтит camphora (L.) } \\
\text { J.Presl }\end{array}$ & Long não & GL & LC \\
\hline \multirow[t]{2}{*}{124} & Litsea glutinosa (Lour.) Roxb. & Bời lời & B & $\mathrm{T}$ \\
\hline & 29. Lecythidaceae & Họ Chiếc & & \\
\hline 125 & $\begin{array}{l}\text { Barringtonia acutangula (L.) } \\
\text { Gaertn. }\end{array}$ & Lộc vừng & GN & LC \\
\hline
\end{tabular}




\begin{tabular}{|c|c|c|c|c|}
\hline STT & Tên khoa học & Tên việt nam & Dạng thân & $\begin{array}{l}\text { Công } \\
\text { dụng }\end{array}$ \\
\hline & 30. Leeaceae & Họ Gối hạt & & \\
\hline \multirow[t]{2}{*}{126} & Leea rubra Blume ex Spreng. & Gối hạt & B & $\mathrm{T}$ \\
\hline & 31. Loranthaceae & Họ Chùm gởi & & \\
\hline \multirow[t]{2}{*}{127} & Dendrophtoe pentandra (L.) Miq. & Mộc ký & BKS & $\mathrm{T}$ \\
\hline & 32. Malvaceae & Họ Bông & & \\
\hline 128 & $\begin{array}{l}\text { Abelmoschus esculentus (L.) } \\
\text { Moench. }\end{array}$ & Bụp bắp & $\mathrm{C}$ & $\mathrm{T}$ \\
\hline 129 & $\begin{array}{l}\text { Abelmoschatus moschatus } \\
\text { Medicus. }\end{array}$ & Bụp vang & $\mathrm{C}$ & $\mathrm{T}$ \\
\hline 130 & Abutilon indicum (L.) Sweet & Cối xay & $\mathrm{C}$ & $\mathrm{T}$ \\
\hline 131 & Hibiscus mutabilis $\mathrm{L}$. & Phù dung & $\mathrm{B}$ & \\
\hline 132 & Hibiscus tiliaceus L. & Bụp tra & GN & $\mathrm{T}$ \\
\hline 133 & Melochia corchorifolia $\mathrm{L}$. & Trứng cua lá bố & $\mathrm{C}$ & $\mathrm{T}$ \\
\hline 134 & $\begin{array}{l}\text { Pavonia repanda (J.E. Sm.) } \\
\text { Spreng. }\end{array}$ & Ké nở & $\mathrm{C}$ & $\mathrm{T}$ \\
\hline 135 & Sida acuta Burm.f. & Chổi đực & $\mathrm{C}$ & \\
\hline 136 & $\begin{array}{l}\text { Thespesis populnea (L.) Soland. } \\
\text { ex Correa. }\end{array}$ & Tra lâm vồ & GL & G \\
\hline \multirow[t]{2}{*}{137} & Urena lobata $\mathrm{L}$. & Ké hoa đào & $\mathrm{B}$ & $\mathrm{T}$ \\
\hline & 33. Melastomataceae & Họ Mua & & \\
\hline \multirow[t]{2}{*}{138} & Melastoma affine D. Don & Mua & $\mathrm{B}$ & \\
\hline & 34. Meliaceae & Họ Xoan & & \\
\hline \multirow[t]{2}{*}{139} & Xylocarpus granatum J. Koenig & Xu ổi & GL & $\mathrm{G}$ \\
\hline & 35. Moraceae & Họ Dâu tằm & & \\
\hline 140 & Ficus benjamina $\mathrm{L}$. & $\mathrm{Si}$ & GL & LC \\
\hline 141 & Ficus elastica Roxb. & Đa búp đỏ & GL & $\mathrm{LC}$ \\
\hline 142 & $\begin{array}{l}\text { Ficus hirta subsp. roxburghii } \\
\text { (King) C.C.Berg }\end{array}$ & Ngái khỉ & B & $\mathrm{T}$ \\
\hline 143 & Ficus microcarpa L.f. & Gừa & GL & LC \\
\hline 144 & Ficus racemosa $\mathrm{L}$. & Sung & GL & $\mathrm{LC}$ \\
\hline 145 & Ficus religiosa $\mathrm{L}$. & Bồ đề & GL & $\mathrm{LC}$ \\
\hline 146 & Ficus rumphii Blume & Lâm vồ & GL & \\
\hline \multirow[t]{2}{*}{147} & Ficus superba Miq. & Sộp & GL & \\
\hline & 36. Myrsinaceae & Họ Cơm nguội & & \\
\hline \multirow[t]{2}{*}{148} & $\begin{array}{l}\text { Aegiceras corniculatum (L.) } \\
\text { Blanco }\end{array}$ & Sú & GN & $\mathrm{T}$ \\
\hline & 37. Myrtaceae & Họ Sim & & \\
\hline 149 & Melaleuca cajuputi Powel. & Tràm & GN & $\mathrm{G}$ \\
\hline 150 & Syzygium cumini (L.) Druce. & Trâm mốc & GL & \\
\hline
\end{tabular}




\begin{tabular}{|c|c|c|c|c|}
\hline STT & Tên khoa học & Tên việt nam & Dạng thân & $\begin{array}{l}\text { Công } \\
\text { dụng }\end{array}$ \\
\hline \multirow[t]{2}{*}{151} & $\begin{array}{l}\text { Syzygium oblatum (Roxb.) Wall. } \\
\text { ex A.M.Cowan \& Cowan }\end{array}$ & Trâm bộng & GN & $\mathrm{G}$ \\
\hline & 38. Nelumbonaceae & Họ Sen & & \\
\hline \multirow[t]{2}{*}{152} & Nelumbo nucifera Gaertn. & Sen & $\mathrm{C}$ & $\mathrm{TP}$ \\
\hline & 39. Nyctaginaceae & Họ Hoa giấy & & \\
\hline \multirow[t]{2}{*}{153} & Boerhavia diffusa $\mathrm{L}$. & Nam sâm & $\mathrm{C}$ & $\mathrm{T}$ \\
\hline & 40. Nymphaeaceae & Họ Súng & & \\
\hline \multirow[t]{2}{*}{154} & $\begin{array}{l}\text { Nymphaea rubra Roxb. ex } \\
\text { Andrews }\end{array}$ & Súng đỏ & $\mathrm{C}$ & $\mathrm{TP}$ \\
\hline & 41. Oleaceae & Họ Nhài & & \\
\hline \multirow[t]{2}{*}{155} & Jasminum sambac (L.) Aiton & Lài & $\mathrm{B}$ & $\mathrm{LC}$ \\
\hline & 42. Onagraceae & Họ Rau mương & & \\
\hline 156 & Ludwigia adscendens (L.) H.Hara & Rau mương & $\mathrm{C}$ & $\mathrm{T}$ \\
\hline 157 & Ludwigia epilobioides Maxim & Rau mương hẹp & $\mathrm{C}$ & $\mathrm{T}$ \\
\hline \multirow[t]{2}{*}{158} & $\begin{array}{l}\text { Ludwigia hyssopifolia (G.Don) } \\
\text { Exell }\end{array}$ & Rau mương thon & $\mathrm{C}$ & \\
\hline & 43. Oxalidaceae & Họ Me đất & & \\
\hline \multirow[t]{2}{*}{159} & Oxalis corniculata $\mathrm{L}$. & Me đất & $\mathrm{C}$ & $\mathrm{T}$ \\
\hline & 44. Passifloraceae & Họ Lạc tiên & & \\
\hline \multirow[t]{2}{*}{160} & Passiflora foetida $\mathrm{L}$. & Nhãn lồng & DL & $\mathrm{T}$ \\
\hline & 45. Phyllanthaceae & Họ Diệp hạ châu & & \\
\hline 161 & Phyllanthus acidus (L.) Skeels & Chùm ruột & GN & $\mathrm{TP}$ \\
\hline 162 & $\begin{array}{l}\text { Phyllanthus amarus Schumach. \& } \\
\text { Thonn. }\end{array}$ & Chó đẻ xanh & $\mathrm{C}$ & $\mathrm{T}$ \\
\hline 163 & Phyllanthus reticulatus Poir. & Phèn đen & $\mathrm{B}$ & $\mathrm{T}$ \\
\hline 164 & Phyllanthus urinaria L. & Chó đẻ răng cưa & $\mathrm{C}$ & $\mathrm{T}$ \\
\hline \multirow[t]{2}{*}{165} & Sauropus rostratus Miq. & Cam xũng & $\mathrm{B}$ & \\
\hline & 46. Phytolaccaceae & Họ Thưọng lục & & \\
\hline \multirow[t]{2}{*}{166} & Phytolacca americana L. & Thượng lục & $\mathrm{C}$ & \\
\hline & 47. Piperaceae & Họ Hồ tiêu & & \\
\hline \multirow[t]{2}{*}{167} & Peperomia pellucida (L.) Kunth & Càng cua & $\mathrm{C}$ & $\mathrm{TP}$ \\
\hline & 48. Plantaginaceae & Họ Mã đề & & \\
\hline 168 & Plantago major $\mathrm{L}$. & Mã đề & $\mathrm{C}$ & $\mathrm{T}$ \\
\hline 169 & Scoparia dulcis L. & Cam thảo nam & $\mathrm{C}$ & $\mathrm{T}$ \\
\hline \multirow[t]{2}{*}{170} & $\begin{array}{l}\text { Limnophila aromatica (Lam.) } \\
\text { Merr. }\end{array}$ & Ôm & $\mathrm{C}$ & \\
\hline & 49. Polygonaceae & Họ Rau răm & & \\
\hline 171 & Polygonum barbatum L. & Nghể trắng & $\mathrm{C}$ & $\mathrm{T}$ \\
\hline
\end{tabular}




\begin{tabular}{|c|c|c|c|c|}
\hline STT & Tên khoa học & Tên việt nam & Dạng thân & $\begin{array}{l}\text { Công } \\
\text { dụng }\end{array}$ \\
\hline \multirow[t]{2}{*}{172} & Polygonum tomentosum Willd. & Nghể & $\mathrm{C}$ & \\
\hline & 50. Portulacaceae & Họ Rau sam & & \\
\hline \multirow[t]{2}{*}{173} & Portulaca oleracea $\mathrm{L}$. & Rau sam & $\mathrm{C}$ & $\mathrm{T}$ \\
\hline & 51. Rhizophoraceae & Họ Đước & & \\
\hline 174 & Bruguiera sexangula (Lour.) Poir. & Vẹt đen & GL & G \\
\hline 175 & $\begin{array}{l}\text { Ceriops decandra (Griff.) } \\
\text { W.Theob. }\end{array}$ & Dà đen & GN & \\
\hline 176 & Rhizophora apiculata Blume & Đước đôi & GL & $\mathrm{G}$ \\
\hline \multirow[t]{2}{*}{177} & Rhizophora mисronata Poir. & Đưng & GN & \\
\hline & 52. Rubiaceae & Họ Cà phê & & \\
\hline 178 & Hedyotis diffusa Willd. & $\begin{array}{l}\text { Bạch hoa xà thiệt } \\
\text { thảo }\end{array}$ & $\mathrm{C}$ & $\mathrm{T}$ \\
\hline 179 & Ixora coccinea $\mathrm{L}$. & Trang hoa đỏ & $\mathrm{B}$ & $\mathrm{LC}$ \\
\hline 180 & Morinda citrifolia $\mathrm{L}$. & Nhàu & GN & $\mathrm{T}$ \\
\hline 181 & Paederia linearis Hook.f. & Thúi địt & $\mathrm{DL}$ & $\mathrm{T}$ \\
\hline 182 & Psychotria serpens $\mathrm{L}$. & Lấu bò & GL & \\
\hline \multirow[t]{2}{*}{183} & $\begin{array}{l}\text { Scyphiphora hydrophylacea } \\
\text { C.F.Gaertn. }\end{array}$ & Côi & B & \\
\hline & $\begin{array}{l}\text { 53. Santalaceae } \\
\end{array}$ & Họ Đàn hương & & \\
\hline 184 & $\begin{array}{l}\text { Viscum cruciatum Sieber ex } \\
\text { Boiss. }\end{array}$ & Ghi đông phương & BKS & $\mathrm{T}$ \\
\hline \multirow[t]{2}{*}{185} & Viscum ovalifolium DC. & Ghi lá xoan & BKS & $\mathrm{T}$ \\
\hline & 54. Sapindaceae & Họ Nhãn & & \\
\hline \multirow[t]{2}{*}{186} & Cardiospermum halicacabum L. & Tầm phỏng & DL & $\mathrm{T}$ \\
\hline & 55. Scrophulariaceae & Họ Hoa mõm sói & & \\
\hline 187 & Bacopa monnieri (L.) Wettst. & Rau đắng biển & $\mathrm{C}$ & $\mathrm{T}$ \\
\hline 188 & $\begin{array}{l}\text { Lindernia anagallis (Burm.f.) } \\
\text { Pennell }\end{array}$ & Lũ̃ đằng cong & $\mathrm{C}$ & \\
\hline 189 & Lindernia crustacea (L.) F.Muell. & Lữ đằng & $\mathrm{C}$ & $\mathrm{T}$ \\
\hline \multirow[t]{2}{*}{190} & Lindernia pierreana Bonati & Lữ đằng Pierre & $\mathrm{C}$ & \\
\hline & 56. Solanaceae & Họ Cà & & \\
\hline 191 & Solanum americanum Mill. & Lù lù đực & $\mathrm{C}$ & $\mathrm{TP}$ \\
\hline 192 & Solanum erianthum D. Don & Ngoi & $\mathrm{B}$ & \\
\hline \multirow[t]{2}{*}{193} & Physalis angulata $\mathrm{L}$. & Lù lù cạnh & $\mathrm{C}$ & $\mathrm{T}$ \\
\hline & 57. Sonneratiaceae & Họ Bần & & \\
\hline 194 & Sonneratia caseolaris (L.) Engl. & Bần chua & GN & \\
\hline 195 & Sonneratia alba J.E. Smith. & Bần trắng & GN & $\mathrm{T}$ \\
\hline 196 & Sonneratia ovata Backer & Bần trứng & GN & $\mathrm{G}$ \\
\hline
\end{tabular}




\begin{tabular}{|c|c|c|c|c|}
\hline STT & Tên khoa học & Tên việt nam & Dạng thân & $\begin{array}{l}\text { Công } \\
\text { dụng }\end{array}$ \\
\hline & 58. Sterculiaceae & Họ Trôm & & \\
\hline 197 & Helicteres hirsute Lour. & Dó lông & B & $\mathrm{T}$ \\
\hline \multirow[t]{2}{*}{198} & Heritiera littoralis Dryand. & Cui & GN & $\mathrm{T}$ \\
\hline & 59. Tiliaceae & Họ Cò ke & & \\
\hline 199 & $\begin{array}{l}\text { Colona auriculata (H.Baill) } \\
\text { Craib. }\end{array}$ & Bồ an & B & $\mathrm{T}$ \\
\hline \multirow[t]{2}{*}{200} & Corchorus olitorius L. & Đay & $\mathrm{C}$ & $\mathrm{T}$ \\
\hline & 60. Ulmaceae & Họ Sếu & & \\
\hline \multirow[t]{2}{*}{201} & Trema orientalis (L.) BL. & Trần mai đông & B & $\mathrm{T}$ \\
\hline & 61. Urticaceae & Họ Cây ngứa & & \\
\hline \multirow[t]{2}{*}{202} & Pouzolzia zeylanica (L.) Benn. & Thuốc vòi & $\mathrm{C}$ & $\mathrm{T}$ \\
\hline & 62. Verbenaceae & Họ Cỏ roi ngụaa & & \\
\hline 203 & Avicennia marina (Forssk.) Vierh. & Mấm đen & GN & $\mathrm{T}$ \\
\hline 204 & Avicennia officinalis $\mathrm{L}$. & Mấm & GL & G \\
\hline 205 & Clerodendrum inerme (L.) Gaertn. & Ngọc nữ biển & $\mathrm{B}$ & $\mathrm{T}$ \\
\hline 206 & Clerodendrum paniculatum $\mathrm{L}$. & Ngọc nữ đỏ & $\mathrm{B}$ & $\mathrm{T}$ \\
\hline 207 & $\begin{array}{l}\text { Clerodendrum petasites (Lour.) } \\
\text { S.Moore }\end{array}$ & Bạch đồng nữ & B & $\mathrm{T}$ \\
\hline 208 & Gmelina asiatica $\mathrm{L}$. & Tu hú & B & $\mathrm{LC}$ \\
\hline 209 & Lantana camara $\mathrm{L}$. & Thơm ổi & B & LC \\
\hline 210 & Premna serratifolia $\mathrm{L}$ & Cách & $\mathrm{B}$ & \\
\hline 211 & Vitex negundo $\mathrm{L}$. & Ngũ trảo & GN & $\mathrm{T}$ \\
\hline \multirow[t]{2}{*}{212} & $\begin{array}{l}\text { Vitex trifolia subsp. litoralis } \\
\text { Steenis }\end{array}$ & Từ bi 3 lá & GN & $\mathrm{T}$ \\
\hline & 63. Vitaceae & Họ Nho & & \\
\hline 213 & Cayratia trifolia (L.) Domin & Vác & DL & $\mathrm{T}$ \\
\hline \multirow[t]{3}{*}{214} & Cissus repens Lam. & Hồ đằng & DL & $\mathrm{T}$ \\
\hline & LILIOPSIDA & LỚP HÀNH & & \\
\hline & 64. Agavaceae & Họ Agao & & \\
\hline \multirow[t]{2}{*}{215} & $\begin{array}{l}\text { Dracaena fragrans (L.) Ker.- } \\
\text { Gawl. }\end{array}$ & Phất dụ & B & $\mathrm{LC}$ \\
\hline & 65. Alismataceae & Họ Trạch tả & & \\
\hline 216 & Limnocharis flava (L.) Buchenau & Kèo nèo & $\mathrm{C}$ & $\mathrm{TP}$ \\
\hline \multirow[t]{2}{*}{217} & Sagittaria sagittaefolia $\mathrm{L}$ & Từ cô & $\mathrm{C}$ & $\mathrm{T}$ \\
\hline & 66. Araceae & Họ Ráy & & \\
\hline 218 & Lasia spinosa $(\mathrm{L}$.$) Thwaites$ & Chóc gai & $\mathrm{C}$ & $\mathrm{T}$ \\
\hline 219 & $\begin{array}{l}\text { Aglaodorum griffithii (Schott) } \\
\text { Schott. }\end{array}$ & Mái dầm & $\mathrm{C}$ & $\mathrm{T}$ \\
\hline
\end{tabular}




\begin{tabular}{|c|c|c|c|c|}
\hline STT & Tên khoa học & Tên việt nam & Dạng thân & $\begin{array}{l}\text { Công } \\
\text { dụng }\end{array}$ \\
\hline 220 & Colocasia esculenta (L.) Schott & Môn nước & $\mathrm{C}$ & $\mathrm{TP}$ \\
\hline 221 & Pistia stratiotes $\mathrm{L}$. & Bèo cái & $\mathrm{C}$ & \\
\hline 222 & $\begin{array}{l}\text { Typhonium flagelliforme (Lodd.) } \\
\text { Blume }\end{array}$ & Bán hạ liên & $\mathrm{C}$ & $\mathrm{T}$ \\
\hline \multirow[t]{2}{*}{223} & Typhonium trilobatum (L.) Schott & Bán hạ ba thùy & $\mathrm{C}$ & $\mathrm{T}$ \\
\hline & 67. Arecaceae & Họ Cau dừa & & \\
\hline 224 & Caryota mitis Lour. & Đủng đỉnh & B & $\mathrm{LC}$ \\
\hline 225 & Nypa fruticans Wurmb & Dừa nước & $\mathrm{B}$ & $\mathrm{TP}$ \\
\hline \multirow[t]{2}{*}{226} & Phoenix paludosa Roxb. & Chà là biển & $\mathrm{C}$ & \\
\hline & 68. Asparagaceae & Họ Măng tây & & \\
\hline \multirow[t]{2}{*}{227} & $\begin{array}{l}\text { Asparagus cochinchinensis } \\
\text { (Lour.) Merr. }\end{array}$ & Thiên môn & DL & $\mathrm{T}$ \\
\hline & 69. Commelinaceae & Họ Thài lài & & \\
\hline 228 & Commelina diffusa Burm.f. & Rau trai & $\mathrm{C}$ & $\mathrm{T}$ \\
\hline 229 & Commelina benghalensis L. & Trai ấn & $\mathrm{C}$ & $\mathrm{T}$ \\
\hline \multirow[t]{2}{*}{230} & Commelina communis $\mathrm{L}$. & Trai thường & $\mathrm{C}$ & \\
\hline & 70. Costaceae & Họ Mía dò & & \\
\hline \multirow[t]{2}{*}{231} & $\begin{array}{l}\text { Cheilocostus speciosus (J.Koenig) } \\
\text { C.D.Specht }\end{array}$ & Cát lồi & $\mathrm{C}$ & $\mathrm{LC}$ \\
\hline & 71. Cyperaceae & Họ Lác & & \\
\hline 232 & Cyperus iria $\mathrm{L}$. & Cú rận & $\mathrm{C}$ & $\mathrm{T}$ \\
\hline 233 & Cyperus castaneus Willd. & Cú rơm & $\mathrm{C}$ & \\
\hline 234 & Cyperus compressus $\mathrm{L}$. & Cú dẹp & $\mathrm{C}$ & \\
\hline 235 & Cyperus difformis $\mathrm{L}$. & Cỏ chao & $\mathrm{C}$ & \\
\hline 236 & Cyperus digitatus Roxb. & U du tia & $\mathrm{C}$ & GD \\
\hline 237 & Cyperus elatus $\mathrm{L}$ & U ru & $\mathrm{C}$ & \\
\hline 238 & Cyperus grandis C.B.Clarke & $\mathrm{U}$ du to & $\mathrm{C}$ & GD \\
\hline 239 & Cyperus halpan $\mathrm{L}$. & Cú rơm & $\mathrm{C}$ & \\
\hline 240 & Cyperus malaccensis Lam. & Lác nước & $\mathrm{C}$ & $\mathrm{T}$ \\
\hline 241 & Cyperus pilosus Vahl & Lác lông & $\mathrm{C}$ & \\
\hline 242 & Cyperus polystachyos Rottb. & Cú ma & $\mathrm{C}$ & GD \\
\hline 243 & $\begin{array}{l}\text { Cyperus radians Nees \& Mey. ex } \\
\text { Nees }\end{array}$ & Cú xạ & $\mathrm{C}$ & \\
\hline 244 & Cyperus rotundus $\mathrm{L}$. & Cỏ cú, hương phụ & $\mathrm{C}$ & $\mathrm{T}$ \\
\hline 245 & Cyperus sanguinolentus Vahl & Cú màu huyết & $\mathrm{C}$ & \\
\hline 246 & Cyperus stoloniferus Vahl & Cú biển & $\mathrm{C}$ & $\mathrm{T}$ \\
\hline 247 & $\begin{array}{l}\text { Eleocharis dulcis (Burm.f.) Trin. } \\
\text { ex Hensch. }\end{array}$ & Năng ngọt & $\mathrm{C}$ & $\mathrm{T}$ \\
\hline
\end{tabular}




\begin{tabular}{|c|c|c|c|c|}
\hline STT & Tên khoa học & Tên việt nam & Dạng thân & $\begin{array}{l}\text { Công } \\
\text { dụng }\end{array}$ \\
\hline 248 & Fimbristylis miliacea (L.) Vahl. & Cỏ chác & $\mathrm{C}$ & $\mathrm{T}$ \\
\hline 249 & $\begin{array}{l}\text { Fimbristylis subspicata Nees \& } \\
\text { Meg. }\end{array}$ & Mạo thư gié & $\mathrm{C}$ & \\
\hline \multirow[t]{2}{*}{250} & Scirpus littoralis Schrab. & Lác biển & $\mathrm{C}$ & \\
\hline & 72. Flagellariaceae & Họ Mây nước & & \\
\hline \multirow[t]{2}{*}{251} & Flagellaria indica $\mathrm{L}$. & Mây nước & DL & $\mathrm{T}$ \\
\hline & 73. Pandanaceae & Họ Dứa gai & & \\
\hline \multirow[t]{2}{*}{252} & Pandanus odoratissimus L. f. & Dứa gai & $\mathrm{B}$ & $\mathrm{T}$ \\
\hline & 74. Poaceae & Họ Hòa thảo & & \\
\hline 253 & $\begin{array}{l}\text { Axonopus compressus (Sw.) } \\
\text { P.Beauv. }\end{array}$ & Cỏ lá gừng & $\mathrm{C}$ & $\mathrm{LC}$ \\
\hline 254 & Chloris barbata $\mathrm{Sw}$. & Lục lông & $\mathrm{C}$ & \\
\hline 255 & $\begin{array}{l}\text { Chrysopogon aciculatus (Retz.) } \\
\text { Trin }\end{array}$ & Cỏ may & $\mathrm{C}$ & $\mathrm{T}$ \\
\hline 256 & Cynodon dactylon (L.) Pers. & Cỏ gà & $\mathrm{C}$ & \\
\hline 257 & $\begin{array}{l}\text { Dactyloctenium aegyptium (L.) } \\
\text { Willd. }\end{array}$ & Cỏ chân gà & $\mathrm{C}$ & $\mathrm{T}$ \\
\hline 258 & Echinochloa colona (L.) Link & Cỏ lòng vực & $\mathrm{C}$ & \\
\hline 259 & Eleusine indica (L.) Gaertn. & Mần trâu & $\mathrm{C}$ & $\mathrm{T}$ \\
\hline 260 & $\begin{array}{l}\text { Eriochloa procera (Retz.) } \\
\text { C.E.Hubb. }\end{array}$ & Cỏ mật & $\mathrm{C}$ & \\
\hline 261 & Imperata cylindrica (L.) Raeusch. & Cỏ tranh & $\mathrm{C}$ & $\mathrm{T}$ \\
\hline 262 & Oryza sativa $\mathrm{L}$ & Lúa & $\mathrm{C}$ & \\
\hline 263 & Panicum repens $\mathrm{L}$. & Cỏ ống & $\mathrm{C}$ & $\mathrm{T}$ \\
\hline 264 & Paspalum vaginatum Swartz. & San sát & $\mathrm{C}$ & $\mathrm{T}$ \\
\hline 265 & Phragmites vallatoria (L.) Veldk. & Sậy & $\mathrm{C}$ & $\mathrm{T}$ \\
\hline 266 & Setaria palmifolia (Koen.) Staf. & Cỏ lá tre & $\mathrm{C}$ & \\
\hline \multirow[t]{2}{*}{267} & Sporobolus virginicus (L.) Kunth & Cỏ cáy & $\mathrm{C}$ & \\
\hline & 75. Pontederiaceae & Họ Lục bình & & \\
\hline \multirow[t]{2}{*}{268} & $\begin{array}{l}\text { Eichhornia crassipes (Mart.) } \\
\text { Solms }\end{array}$ & Lục bình & $\mathrm{C}$ & $\mathrm{T}$ \\
\hline & 76. Typhaceae & Họ Hương bồ & & \\
\hline \multirow[t]{2}{*}{269} & Typha angustifolia $\mathrm{L}$. & Bồn bồn & $\mathrm{C}$ & $\mathrm{TP}$ \\
\hline & 77. Xyridaceae & Họ Hoàng đầu & & \\
\hline \multirow[t]{2}{*}{270} & Xyris indica $\mathrm{L}$. & Hoàng đầu Ấn & $\mathrm{C}$ & $\mathrm{T}$ \\
\hline & 78. Zingiberaceae & Họ Gù̀ng & & \\
\hline 271 & Curcuma longa $\mathrm{L}$. & Nghệ & $\mathrm{C}$ & $\mathrm{T}$ \\
\hline 272 & Zingiber cochinchinensis Gagn. & Gừng nam bộ & $\mathrm{C}$ & $\mathrm{T}$ \\
\hline
\end{tabular}




\begin{tabular}{|c|l|l|l|c|}
\hline STT & \multicolumn{1}{|c|}{ Tên khoa học } & \multicolumn{1}{|c|}{ Tên việt nam } & Dạng thân & $\begin{array}{c}\text { Công } \\
\text { dụng }\end{array}$ \\
\hline 273 & $\begin{array}{l}\text { Zingiber zerumbet } \text { (L.) Roscoe ex } \\
\text { Sm. }\end{array}$ & Ngải xanh & $\mathrm{C}$ & $\mathrm{T}$ \\
\hline
\end{tabular}

Ghi chú: BKS. Bán ký sinh; GL. Gỗ lớn; GN. Gỗ nhỏ; DL. Dây leo; B. Bụi/bụi trườn; C. Thân thảo; T. Làm thuốc; LC. Làm cảnh; G. Cho gỗ; TP. Làm thực phẩm; GD. Gia dụng

Nguồn: Kết quả phân tích dữ liệu của nhóm nghiên cứu

Từ Bảng 1, phân tích sâu hơn về ngành Ngọc lan (Magnoliophyta) cho kết quả như sau: lớp Ngọc lan (Magnoliopsida) chiếm ưu thế với số loài là 207 (chiếm 75,8\% tổng số loài), số chi là 164 (chiếm 78,5\% tổng số chi), số họ là 59 (chiếm 75,6\% tổng số họ); lớp Hành (Liliopsida) có tỷ lệ thấp hơn, với số loài là 59 (chiếm 21,6\%), số chi là 40 (chiếm 19,1\%) và số họ là 15 (chiếm 19,2\%).

Để đánh giá tính đa dạng loài của khu vực nghiên cứu, 10 họ và 10 chi có số lượng loài nhiều nhất cũng được thống kê. Theo kết quả Bảng 1,10 họ có số lượng loài nhiều nhất với 128 loài chiếm $46,9 \%$ tổng số loài. Trong đó, họ có số lượng loài nhiều nhất phải kể đến là họ Đậu (Fabaceae) có 20 loài, kế đến là họ Lác (Cyperaceae) có 19 loài, Cúc (Asteraceae) có 18 loài, họ Hòa thảo (Poaceae) có 15 loài, họ Thầu dầu (Euphorbiaceae) có 11 loài, họ Bông (Malvaceae) và họ Cỏ roi ngựa (Verbenaceae) mỗi họ có 10 loài, họ Thiên lý (Asclepiadaceae) có 9 loài, và sau cùng là họ Trúc đào (Apocynaceae) và họ Dâu tẳm (Moraceae) mỗi họ có 8 loài.

Kết quả thống kê 10 chi có số lượng loài nhiều nhất với 49 loài chiếm $17,9 \%$ tổng số loài ở khu vực nghiên cứu. Trong đó, chi có số lượng loài nhiều nhất là chi Lác (Cyperus) có 15 loài, kế đến là chi Sung (Ficus) có 8 loài, tiếp đến là chi Bìm bìm (Ipomoea) và chi Diệp hạ châu (Phyllanthus) mỗi chi đều có 4 loài và sau cùng là các chi Bòng bòng (Lygodium), chi Rau mương (Ludwigia), chi Lữ đằng (Lindernia), chi Bần (Sonneratia), chi Ngọc nữ (Cledodendrum), chi Trai (Commelina) mỗi chi đều có 3 loài.

\subsection{Các dạng thân của thục vật}

Hiện nay chưa có sự thống nhất về quan điểm phân chia dạng thân của thực vật. Vì vậy, trong nghiên cứu này chúng tôi sử dụng cách phân chia dạng thân của T. N. Nguyen (1997, 2007) để xác định dạng thân của thực vật trong khu vực nghiên cứu, theo cách phân chia này thì dạng thân của thực vật được chia làm 6 nhóm gồm: cây thân thảo $(\mathrm{C})$, cây bụi/bụi trườn $(\mathrm{B})$, dây leo (DL), cây gỗ nhỏ (GN), cây gỗ lớn (GL) và bán kí sinh (BKS) (Bảng 1). Trong đó, nhóm cây thân thảo có 141 loài (chiếm 51,6\% tổng số loài), nhóm này gồm các cây sống ở các vùng đất ngập nước, đất canh tác, trảng cỏ, ven đường đi và ven kênh rạch; tập trung chủ yếu vào các họ như họ Hòa thảo (Poaceae), họ Lác (Cyperaceae), họ Hoa mõm sói (Scrophulariaceae), họ Hoa môi (Lamiaceae), họ Cúc (Asteraceae), họ Rau dền (Amaranthaceae),... Tiếp đến là nhóm cây bụi/bụi trườn có 46 loài (chiếm 16,8\%), nhóm này gặp nhiều ở ven bờ kênh rạch, rừng ngập mặn, ven đường đi, tập trung chủ yếu vào các họ như họ Cỏ roi ngựa (Verbenaceae), họ Đậu (Fabaceae), họ Thầu dầu (Euphorbiaceae),...Nhóm dây leo có 36 loài (chiếm 13,2\%), nhóm này gặp nhiều ở dưới tán rừng ngập mặn và ven kênh rạch, chủ yếu là các họ Bìm bìm (Convolvulaceae), họ Thiên lý (Asclepiadaceae), họ Ráng a diệp (Schizeaceae), họ Bầu bí (Cucurbitaceae), họ Nho (Vitaceae), ... Nhóm cây gỗ nhỏ và gỗ lớn lần lượt có 25 loài (chiếm 9,2\%) và 22 loài (chiếm $8,1 \%$ ), nhóm này gồm các cây sống ở rừng 
ngập mặn, ven kênh rạch hay rừng trồng như họ Dâu tằm (Moraceae), họ Đước (Rhizophoraceae), họ Cỏ roi ngựa (Verbenaceae), họ Bần (Sonneratiaceae), họ Dầu (Dipterocarpaceae),... và sau cùng là nhóm bán ký sinh $(\mathrm{BKS})$ có 3 loài (chiếm $1,1 \%$ ), chủ yếu tập trung vào các họ Chùm gởi (Loranthaceae) và họ Đàn hương (Santalaceae).

Như vậy, nhóm cây thân thảo chiếm tỷ trọng cao nhất $(51,6 \%)$ trong số các dạng thân hiện có ở khu vực nghiên cứu, chúng góp phần làm gia tăng tính đa dạng của hệ thực vật, lưu giữ nguồn nước, nơi cư trú của nhiều loài động vật, chống xói mòn và biến đổi khí hậu.

\subsection{Giá trị sử dụng của thục vật}

Theo kết quả Bảng 1, khu vực nghiên cứu có 245 loài chiếm 89,7\% tổng số loài có giá trị sử dụng và được chia làm 5 nhóm công dụng gồm làm thuốc $(\mathrm{T})$, làm cảnh (LC), cho gỗ $(\mathrm{G})$, thực phẩm (TP), gia dụng (GD). Trong đó, nhóm cây làm thuốc có 183 loài (chiếm 67,0\% tổng số loài), các loài cây này thường được sử dụng để chữa trị những bệnh thông thường như cảm cúm, sốt cao, sởi, lở loét, ho, mẩn ngứa, thanh nhiệt, đau răng hay nhiều bệnh khác; kế đến là nhóm cây làm cảnh với 25 loài (chiếm 9,2\%), nhóm này thường có giá trị thẩm mỹ như cho hoa đẹp, bonsai, cho bóng mát và cây cảnh; nhóm cây cho gố với 15 loài (chiếm 5,5\%), thường được sử dụng để lấy gỗ dùng trong xây dựng, đóng các đồ dùng gia đình, tàu thuyền hoặc lấy củi; nhóm cây làm thực phẩm có 15 loài (chiếm 5,5\%) là các loài cây ăn được như cho gia vị, làm rau, cho quả ăn được và các bộ phận khác ăn được; sau cùng là nhóm cây gia dụng với 6 loài (chiếm $1,1 \%$ ), chúng được sử dụng vào nhiều mục đích khác nhau như đan lát, lợp nhà, bệnh dây, dây cột, chất đốt hay các đồ gia công mỹ nghệ. Nhóm có 2 công dụng gồm 4 loài (chiếm 1,5\%) gồm Phi lao (Casuarina equisetifolia) vừa làm thuốc vừa làm cảnh, Sao đen (Hopea odorata) vừa làm cảnh vừa cho gỗ, Điên điển (Sesbania cannabina) và So đũa (Sesbania grandiflora) vừa làm thuốc vừa làm thực phẩm.

\subsection{Các sinh cảnh thục vật}

\section{Sinh cảnh thục vật tụ nhiên}

- Quần hợp thực vật ưu thế Đước (Rhizophora spp.): Quần hợp này gặp nhiều ở xã Trường Long Hòa, Dân Thành và Hiệp Thạnh của thị xã Duyên Hải, chúng thường tập trung thành từng mảng rừng dọc theo biển, hai bên kênh lớn hay ven bờ các đầm nuôi tôm, cua. Bên cạnh hai loài của chi Đước (Rhizophora) chiếm ưu thế là Đước đôi (Rhizophora apiculata) và Đưng (Rhizophora mucronata) còn có một số loài khác tham gia như: Ráng đại (Acrostichum aureum), Ô rô (Acanthus ilicifolius), Vẹt đen (Bruguiera sexangula), Dà đen (Ceriops decandra), Mấm đen (Avicennia marina), Lác biển (Scirpus littoralis), ...

- Quần hợp thực vật ưu thế Mấm (Avicennia spp.): Hai loài Mấm (Avicennia officinalis) và Mấm đen (Avicennia marina) chiếm ưu thế trong quần hợp này, chúng thường phân bố tập trung ở ven hai bờ kênh nội đồng và dọc theo bờ biển nơi có một lớp dày phù sa bồi tụ hàng năm. Tham gia với quần hợp này còn có Giá (Excoecaria agallocha), Dà đen (Ceriops decandra), Đước đôi (Rhizophora apiculata), Cú biển (Cyperus stoloniferus), ... Quần hợp này gặp nhiều ở xã Dân Thành, Long Hữu và Trường Long Hòa.

- Quần hợp thực vật ưu thế Dừa nước (Nypa fruticans): Phân bố nhiều ở các xã Hiệp Thành, Long Toàn và Trường Long Hòa với loài ưu thế là Dừa nước (Nypa fruticans), mọc xen 
còn có Ô rô trắng (Acanthus ebracteatus) và Mái dầm (Aglaodorum griffithii). Bên cạnh đó còn có các loài thực vật khác tham gia như: Bần chua (Sonneratia casaeolaris), Lục bình (Eichhornia crassipes), Ráng đại (Acrostichum aureum), Hải cúc 2 hoa (Wollastonia biflora), ... Đây được xem là quần hợp khá đơn giản về thành phần loài.

- Quần hợp thực vật ưu thế Sậy (Phragmites vallatoria): Gặp nhiều ở những nơi đất trồng bỏ hoang lâu ngày, ven đường đi và các khu vực quy hoạch làm đất thổ cư chưa xây dựng, thành phần loài khá đơn giản, ngoài Sậy (Phragmites vallatoria) chiếm ưu thế còn có một số loài khác tham gia như Bòng bòng leo (Lygodium scandens), Đầu đài mảnh (Tylophora flexuosa), Mai dương (Mimosa pigra), Cỏ tranh (Imperata cylindrica), Cộng sản (Eupatorium odoratum), Chổi đực (Sida acuta) và Nhãn lồng (Passiflora foetida).

- Quần hợp thực vật ưu thế Lức (Pluchea indica): Quần hợp này thường gặp ở những nơi đất bỏ hoang không canh tác, ven các đường đi hay kênh rạch nội đồng. Thành phần loài gồm Lức (Pluchea indica) chiếm ưu thế, mọc xen còn có một số loài khác như: Cỏ tranh (Imperata cylindrica), Cộng sản (Eupatorium odoratum), Bòng bòng (Calotropis gigantea), Mắc cở (Mimosa pudica), Cỏ may (Chrysopogon aciculatus).

- Quần hợp thực vật ưu thế Hải cúc 2 hoa (Wollastonia biflora): Phân bố chủ yếu ở các xã ven biển hay xã có nhiều kênh rạch gần biển như Hiệp Thạnh, Trường Long Hòa, Dân Thành. Bên cạnh loài Hải cúc 2 hoa (Wollastonia biflora) chiếm ưu thế còn có một số loài khác tham gia như: Ô rô (Acanthus ilicifolius), Ráng đại (Acrostichum aureum), Cóc kèn (Derris trifolia), Bần chua (Sonneratia caseolaris), Ngọc nữ biển (Clerodendrum inerme), Bình bát (Annona glabra).

- Quần hợp thực vật ưu thế Muống biển (Ipomoea pes-caprae): Đây là quần hợp thích nghi với các vùng đất cát ven biển, chúng thường mọc thành đám dày, gặp nhiều ở các xã như Trường Long Hòa, Hiệp Thạnh và Dân Thành. Loài Muống biển (Ipomoea pes-caprae) chiếm ưu thế trong quần hợp, mọc xen còn có một số loài khác như: Lác biển (Scirpus littoralis), Cú biển (Cyperus stoloniferus), U du (Cyperus grandis), Rau sam (Portulaca oleracea).

\section{Sinh cảnh thục vật trên đất canh tác}

Sinh cảnh này bao gồm các cây trồng lâu năm và cây hoa màu ngắn ngày như cây ăn quả, ngô, hành, đậu và nhiều loại hoa màu khác. Các loài cây hoang dại mọc xen như: Rau đắng đất (Glinus oppositifolius), Cỏ tam khôi (Trianthema portulacastrum), Trái nổ (Ruellia tuberosa), Dền (Amaranthus lividus), Diếc bờ (Alternanthera sessilis), Chân vịt ấn (Sphaeranthus indicus), Song nha lông (Bidens pilosa), Màn màn tím (Cleome chelidonii), Trai thường (Commelina communis), Ké đầu ngựa (Xanthium inaequilaterum), Trứng cua lá bố (Melochia corchorifolia), Cú ma (Cyperus polystachyos), Cỏ sữa lá lớn (Euphorbia hirta), Muồng tây (Cassia occidentalis), Điên điển (Sesbania cannabina), Ích mẫu (Leonurus artemisia),...Sinh cảnh này hiện diện ở tất cả các xã trên địa bàn thị xã Duyên Hải.

\section{Sinh cảnh thục vật trên đất thổ cu}

Đây là sinh cảnh không có loài chiếm ưu thế, thành phần thực vật chủ yếu là cây thân thảo và dây leo, ít cây bụi và cây gỗ. Các loài hiện diện là những loài phổ biến ở khu vực đồng 
bằng Sông Cửu Long, các loài thường gặp trong quá trình khảo sát thực địa như: Dền gai (Amaranthus spinosus), Bạch đầu ông (Vernonia cinerea), Cỏ sướt (Achyranthes aspera), Đình lịch đứng (Hygrophila erecta), Nhãn lồng (Passiflora foetida), Cỏ lồng vực (Echinochloa colona), Bình bát (Annona glabra), Rau má (Centella asiatica), Cộng sản (Eupatorium odoratum), Bọ xít (Synedrella nodiflora), Vòi voi (Heliotropium indicum), U du (Cyperus grandis), Chó đẻ xanh (Phyllanthus amarus), Chổi đực (Sida acuta), Lù lù đực (Solanum americanum), Súng đỏ (Nymphaea rubra), Vác (Cayratia trifolia),... Sinh cảnh này gặp nhiều ở phường 1, 2, xã Long Hữu và Long Toàn.

\subsection{Thảo luận}

Thị xã Duyên Hải là huyện có diện tích đất tiếp giáp với bờ biển dài nhất (35km trên tổng số $65 \mathrm{~km}$ của toàn tỉnh) của tỉnh Trà Vinh, vì vậy đây được xem là nơi chịu ảnh hưởng nặng nề nhất của quá trình biến đổi khí hậu và mực nước biển dâng. Thế nhưng, hệ thực vật ở đây khá đa dạng và phong phú (273 loài), chúng góp phần hình thành nên các sinh cảnh rừng, tạo vành đai chắn gió, chống xói lở, ngăn mặn và đặc biệt là mang lại nguồn thu nhập lớn cho người dân địa phương thông qua việc áp dụng mô hình nuôi "Tôm - Cua - Rừng" theo hướng phát triển bền vững.

Các sinh cảnh thực vật ở thị xã Duyên Hải đang có chiều hướng suy giảm cả về diện tích lẫn chất lượng rừng do tác động bởi yếu tố con người như: chuyển đổi đất rừng thành đất xây dựng khu dân cư, nhà máy, xí nghiệp; phá rừng để làm vuông tôm; đắp đê ngăn mặn,... Vì vậy, cần có chính sách ưu tiên bảo vệ và phát triển rừng, đặc biệt là rừng ngập mặn, tăng cường công tác tuyên truyền nâng cao nhận thức của người dân về vai trò của rừng, phục hồi và trồng bổ sung các diện tích rừng đã mất, đồng thời cần gắn kết hài hòa giữa công tác bảo vệ và phát triển rừng với phát triển kinh tế hộ gia đình.

Hiện nay có sự phát triển vượt trội và chiếm ưu thế của hai loài thực vật ngoại lai là Mai dương (Mimosa pigra) và Lục bình (Eichhornia crassipes), chúng xâm lấn và dần dần thay thế các loài thực vật bản địa cũng như ngăn chặn dòng chảy làm ảnh hưởng đến giao thông đường thủy. Vì vậy, cần có biện pháp phòng trừ để ngăn chặn sự bùng phát của hai loài thực vật này.

\section{Kết luận}

Kết quả nghiên cứu đã ghi nhận được hệ thực vật ở thị xã Duyên Hải tỉnh Trà Vinh có 273 loài, 209 chi, 78 họ của 2 ngành thực vật bậc cao có mạch là ngành Dương xỉ (Polypodiophyta) và ngành Ngọc lan (Magnoliophyta).

Đã xác định được ở khu vực nghiên cứu có 245 loài có giá trị sử dụng chiếm 89,7\% tổng số loài được nhận diện và được chia thành 5 nhóm công dụng như sau: làm thuốc có 186 loài, làm cảnh có 26 loài, cho gỗ có 15 loài, thực phẩm có 15 loài, và gia dụng có 6 loài.

Thực vật ở thị xã Duyên Hải được chia làm 6 nhóm dạng thân chính, đó là: cây thân thảo có 141 loài, cây bụi/bụi trườn có 46 loài, dây leo có 36 loài, gỗ nhỏ có 25 loài, gỗ lớn có 22 loài và bán ký sinh có 3 loài. 
Đã ghi nhận được 3 kiểu sinh cảnh thực vật ở khu vực nghiên cứu gồm: Sinh cảnh thực vật tự nhiên (có 7 kiểu quần hợp là Quần hợp thực vật uu thế Đuớc (Rhizophora spp.), Quần hơp thực vật uu thế Mấm (Avicennia spp.), Quần hợp thực vật uu thế Dìa nước (Nypa fruticans), Quần hợp thực vật uu thế Sậy (Phragmites vallatoria), Quần hợp thực vật uu thế Lức (Pluchea indica), Quần hợp thực vật ưu thế Hải cúc 2 hoa (Wollastonia biflora) và Quần hơp thực vật ưu thế Muống biển (Ipomoea pes-caprae)), Sinh cảnh thực vật trên đất canh tác và Sinh cảnh thực vật trên đất thổ cư.

\section{Tài liệu tham khảo}

Bộ Khoa học và Công nghệ, \& Viện Khoa học và Công nghệ Việt Nam. (2007). Thưc vật chí Việt Nam [Vietnamese plants]. Hanoi, Vietnam: NXB Khoa học và Kỹ thuật.

Bộ Khoa học và Công nghệ. (2007). Sách Đỏ Việt Nam - Phần thực vật [Vietnam Red book Vegetation part]. Hanoi, Vietnam: NXB Khoa học tự nhiên và Công nghệ.

Braun-Blanquet, J. (1964). Pflanzensoziologie. Grundzüge der vegetationskunde [Plant sociology. Basics of vegetation science] (3rd ed.). Wien, Austria: Springer Verlag.

Do, B. H. (2006). Cây thuốc và động vật làm thuốc ở Việt Nam [Medicinal plants and animals for medicine in Vietnam]. Hanoi, Vietnam: NXB Khoa học và Kỹ thuật.

Do, L. T. (2009). Nhũng cây thuốc và vị thuốc Việt Nam [Vietnamese medicinal plants and herbs]. Hanoi, Vietnam: NXB Y học.

Nguyen, B. T. (1997). Cẩm nang tra cưu và nhận biết các họ thực vật hạt kín ở Việt Nam [Handbook for searching and identifying angiosperms in Vietnam]. Hanoi, Vietnam: NXB Nông nghiệp.

Nguyen, T. N. (1997). Cẩm nang tra cúu đa dạng sinh vật [Biodiversity lookup handbook]. Hanoi, Vietnam: NXB Nông nghiệp.

Nguyen, T. N. (2007). Các phương pháp nghiên cúu thục vật [Plant research methods]. Hanoi, Vietnam: NXB Đại học Quốc gia Hà Nội.

Pham, H. H. (1999). Cây cỏ Việt Nam [An illustrated flora of Vietnam]. Ho Chi Minh, Vietnam: NXB Trẻ.

Vo, C. V. (2012). Tù điển cây thuốc Việt Nam [Dictionary of Vietnamese medicinal plants]. NXB Y học, Hà Nội. 